\title{
Androgens Stimulate Early Stages of Follicular Growth in the Primate Ovary
}

\author{
Keith A. Vendola, Jian Zhou, Oluyemisi O. Adesanya, Stacie J. Weil, and Carolyn A. Bondy \\ Developmental Endocrinology Branch, National Institute of Child Health and Development, National Institutes of Health, Bethesda, \\ Maryland 20892
}

\begin{abstract}
The concept that androgens are atretogenic, derived from murine ovary studies, is difficult to reconcile with the fact that hyperandrogenic women have more developing follicles than normal-cycling women. To evaluate androgen's effects on primate follicular growth and survival, normalcycling rhesus monkeys were treated with placebo-, testosterone-(T), or dihydrotestosterone-sustained release implants, and ovaries were taken for histological analysis after 3-10 d of treatment. Growing preantral and small antral follicles up to $1 \mathrm{~mm}$ in diameter were significantly and progressively increased in number and thecal layer thickness in T-treated monkeys from 3-10 d. Granulosa and thecal cell proliferation, as determined by immunodetection of the Ki67 antigen, were significantly increased in these follicles. Preovulatory follicles ( $>1 \mathrm{~mm}$ ), however, were not increased in number in androgen-treated animals. Follicular atresia was not increased and there were actually significantly fewer apoptotic granulosa cells in the T-treated groups. Dihydrotestosterone treatment had identical effects, indicating that these growth-promoting actions are mediated by the androgen receptor. These findings show that, over the short term at least, androgens are not atretogenic and actually enhance follicular growth and survival in the primate. These new data provide a plausible explanation for the pathogenesis of "polycystic" ovaries in hyperandrogenism. (J. Clin. Invest. 1998. 101:2622-2629.) Key words: granulosa cells • folliculogenesis - mitosis - apoptosis • androgen
\end{abstract}

\section{Introduction}

The regulation of early stages of follicular growth in the primate ovary is poorly understood (1). Estrogens stimulate follicular growth and granulosa cell proliferation in rodents (2-4), but they are inactive or even inhibitory towards follicular growth in primates (5-7). Androgens, on the other hand, are atretogenic in rodents (8-10), but some observations suggest that they may stimulate ovarian growth in humans. Women

Address correspondence to Carolyn A. Bondy, M.D., Ph.D., Bldg. 10, Rm. 10N262, NIH, 10 Center Dr. 1862, Bethesda, MD 20892-1862. Phone: 301-496-6664; FAX: 301-402-2922; E-mail: bondyc@cc1. nichd.nih.gov

Received for publication 23 October 1997 and accepted in revised form 8 April 1998.

The Journal of Clinical Investigation

Volume 101, Number 12, June 1998, 2622-2629

http://www.jci.org with polycystic ovarian syndrome (PCOS $)^{1}$ typically have enlarged ovaries with increased numbers of follicles and increased stromal volume $(11,12)$. PCOS-like morphological and functional changes occur in women as a result of exposure to extraovarian androgens, as in congenital adrenal hyperplasia or androgen-producing tumors (13-15) and in transsexual women treated with testosterone (16-18). This latter group is interesting because the high-dose androgen treatment causes suppression of gonadotropins, and yet their ovaries are not suppressed, but are enlarged with increased numbers of "cystic" follicles and theca-interstitial hyperplasia, meeting the morphological criteria for PCOS (16-18).

These observations suggest that androgens per se may induce ovarian follicular and theca-interstitial growth. To elucidate the acute effects of androgen exposure on the primate ovary, in the present study, normal cycling rhesus monkeys were given subcutaneous implants containing vehicle, testosterone, or dihydrotestosterone, and ovaries were removed after 3-10 d for histomorphometric analysis.

\section{Methods}

Experimental animals. Female rhesus monkeys (Macacca mulatta), 6-13 yr of age, from the NIH Poolesville colony were used in accordance with a protocol approved by the NICHD animal care and use committee. Animals had pellets (Innovative Research of America, Toledo, $\mathrm{OH}$ ) inserted subcutaneously between their shoulder blades under ketamine anesthesia. In the first set of experiments, groups ( $n=4-6)$ received pellets containing vehicle, high-dose testosterone ( $4 \mathrm{mg} / \mathrm{kg}$ per day for $3 \mathrm{~d}$ ), or testosterone ( $400 \mu \mathrm{g} / \mathrm{kg}$ per day for $10 \mathrm{~d}$ ). In a subsequent set of experiments, animals received pellets with placebo, low-dose testosterone ( $20 \mu \mathrm{g} / \mathrm{kg}$ per day for $5 \mathrm{~d}$ ), or dihydrotestosterone (DHT; $145 \mu \mathrm{g} / \mathrm{kg}$ per day for $5 \mathrm{~d}$ ). At the end of the dosing periods, ovariectomies were performed on the monkeys under ketamine anesthesia via a midventral laparotomy. Serum was collected for hormone measurement at the time of pellet placement and at the time of ovariectomy. Serum estradiol, testosterone, DHT, and progesterone levels were measured by RIA at Hazleton Laboratories (Vienna, VA). Ovaries were snap frozen on dry ice and stored at $-70^{\circ} \mathrm{C}$. Entire ovaries were cut into $10-\mu \mathrm{m}$-thick sections along the longitudinal axis on a cryostat at $-15^{\circ} \mathrm{C}$ and thaw mounted onto polyL-lysine-coated slides for morphological and immunocytochemical investigation.

Morphometry. Fresh frozen tissue sections were fixed in 4\% formalin for $10 \mathrm{~min}$, and then stained with hematoxylin and eosin. The largest longitudinal diameter sections from the right and left ovaries of each animal were chosen for morphometric analysis. Ovarian sections were digitized using a SonyXC (Cypress, CA) solid state video camera attached to a Macintosh PowerPC using NIH Image $6.1 \mathrm{im}-$ age analysis software. Whole ovarian sections were outlined by cursor control and areas registered. The areas of the largest section from the left and right ovaries were meaned for each animal and these means were pooled to determine group means. Ovarian capsule thickness

1. Abbreviations used in this paper: DHT, dihydrotestosterone; PCOS, polycystic ovarian syndrome; $\mathrm{T}$, testosterone. 
was measured at the ab-hilar surface also using image analysis capturing images from a microscope at $100 \times$ (Laborlux; Leica Inc., Deerfield, IL). Follicle size was determined by measurement of the largest cross-sectional diameter at a magnification of $200 \times$ for primary follicles and 100 and $50 \times$ for larger follicles. Theca thickness was measured at $100 \times$. All measurements were made independently for right and left ovaries from each animal and the data meaned to obtain final values for each animal. These means were then pooled to obtain group means.

Immunocytochemistry. Immunocytochemistry for Ki67 was performed by the avidin-biotin-immunoperoxidase technique. The mouse anti-human Ki67 serum (Boehringer Mannheim Biochemicals, Indianapolis, IN) was used at a dilution of 1:50. Fresh-frozen tissue sections were fixed in $4 \%$ formalin-PBS for $30 \mathrm{~min}$. After blocking in $1 \%$ hydrogen peroxide- $10 \%$ methanol-PBS, avidin-biotin blocking reagent, and $10 \%$ normal sheep serum, tissue sections were incubated overnight at $4{ }^{\circ} \mathrm{C}$ with mouse anti-human Ki67 antibody or with $1 \%$ PBS as the control. Thereafter, tissue sections were treated with biotinylated sheep anti-mouse IgG (1:40) for $30 \mathrm{~min}$ at room temperature, followed by a 45-min incubation with the avidin-biotinperoxidase complex (Vectastain ABC Elite Peroxidase Kit; Vector Laboratories, Inc., Burlingame, CA). The antigen-antibody complex was visualized by incubation with freshly prepared 3,3'-diaminobenzidine (3,3'-diaminobenzidine Substrate Kit; Vector Laboratories, Inc.), and the tissue was counterstained with methyl green.

In addition, the ApopTag ${ }^{\circledR}$ method for in situ apoptosis detection of programmed cell death was performed. This TUNEL (terminal-deoxynucleotidyl-transferase-mediated, dUTP, nick-end-labeling) method uses the terminal deoxynucleotidyl transferase (TdT) enzyme to catalyze the attachment of digoxigenin-dUTP onto the free 3'-OH ends of apoptotic DNA fragments (Oncor Inc., Gaithersburg, $\mathrm{MD})$. Fresh-frozen tissue sections were fixed in cold acetone and cold 2:1 ethanol:acetate at $-20^{\circ} \mathrm{C}$ for 10 and $5 \mathrm{~min}$, respectively. After blocking with $1 \%$ bovine serum albumin-PBS, tissue sections were incubated for $1 \mathrm{~h}$ at $37^{\circ} \mathrm{C}$ with digoxigenin-dUTP and TdT or with $1 \%$ $\mathrm{PBS}$ as the control. Tissue sections were then incubated in antidigoxigenin peroxidase for $30 \mathrm{~min}$ at room temperature. The antigen-antibody complex was visualized with $3,3^{\prime}$-diaminobenzidine and stained with methyl green as described above.

Quantitative analysis. Ki67 and ApopTag ${ }^{\circledR}$-positive granulosa cells and Ki67-positive theca cells in each group of follicles were counted under direct visualization at $400 \times$ magnification using a Laborlux microscope (Leitz, Rockleigh, NJ). Approximately 100 cells were scored for each follicle and data was expressed as a percentage representing the ratio of positive-staining nuclei to total number of counted nuclei. Mean values for each group were compared by analysis of variance, followed by Fisher's least significant difference test.

\section{Results}

Morphometry. Ovaries of testosterone-treated animals were enlarged with increased antral follicle numbers compared with controls at the macroscopic level (Fig. 1). Figs. 1 and $2 A$ show that testosterone $(\mathrm{T})$ treatment increased maximal ovarian cross-sectional area at both 3 and $10 \mathrm{~d}(P=0.002$ and 0.034 , respectively). Following this trend, testosterone also induced more than a twofold increase in capsular thickness: control group was $78 \pm 8.6 \mu \mathrm{m}$; T 3 Day was $160 \pm 27.8 \mu \mathrm{m}(P=0.005)$, and T 10 Day was $164 \pm 15.2 \mu \mathrm{m}(P=0.004)$.

Total follicle number was increased by 2.5 -fold in the 3 -d treatment group and 4.5 -fold in the 10 -d group (Fig. 2 B). To determine whether specific stages of follicular development were selectively affected by testosterone, follicles were divided into five different classes based on diameter (Table I). Testosterone significantly increased the numbers of all small follicle groups (Fig. 2, $A-D$ ) up to $1 \mathrm{~mm}$ in diameter (Fig. 2, $C$ and
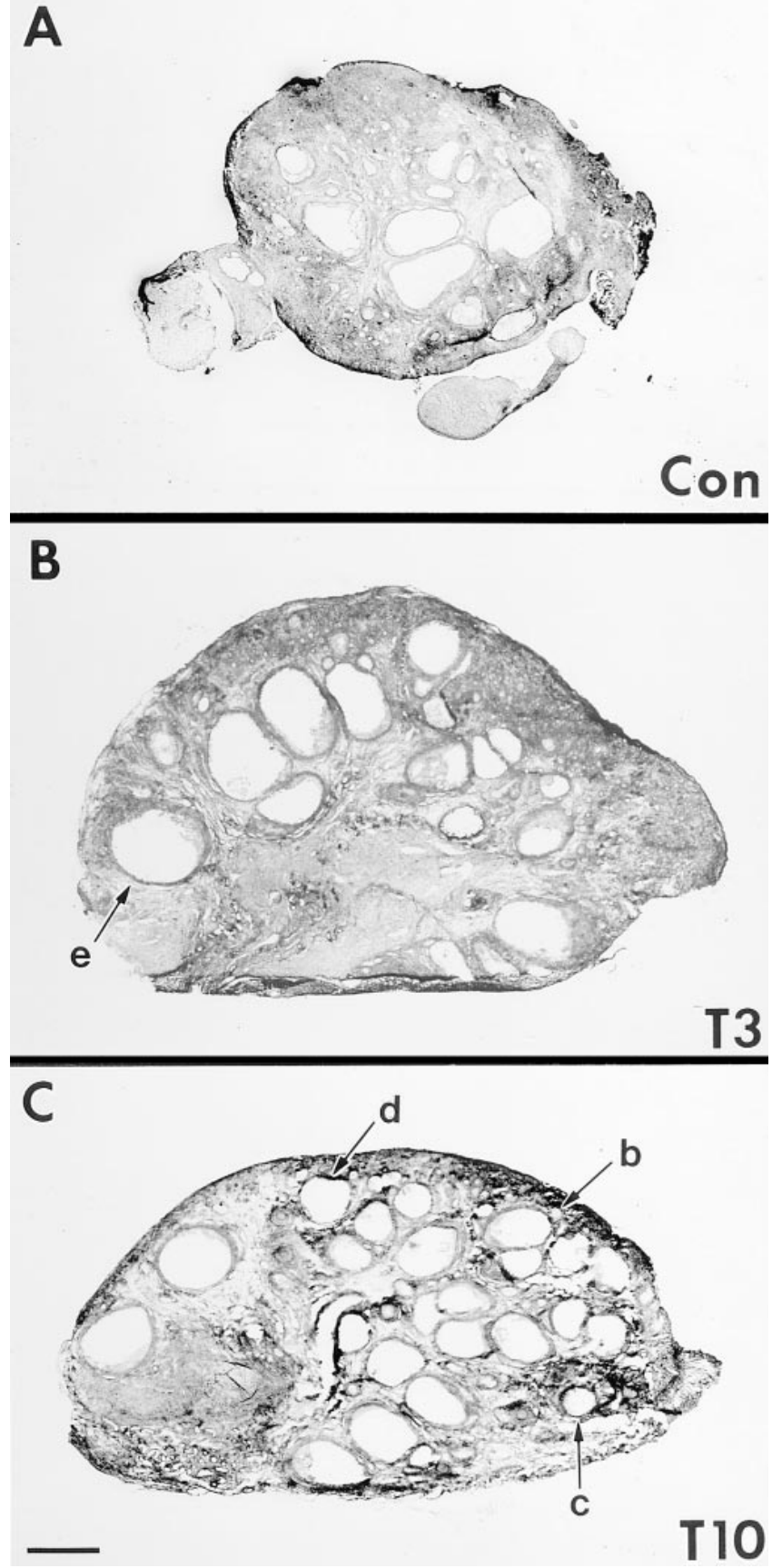

Figure 1. Testosterone treatment increases ovarian size and follicular number. This figure shows representative hematoxylin and eosinstained ovarian sections from placebo $(A), 3$-d testosterone-treated $(T 3, B)$, and $10-d$ testosterone-treated $(T 10, C)$ groups. Typical examples of B-E-sized follicles are indicated by the corresponding small case letters. Bar $=1.25 \mathrm{~mm}$.

$D)$. This includes a 2.7 -fold increase in the number of primary or "A" follicles after $3 \mathrm{~d}(P=0.042)$ and a 4.6-fold $(P=$ $0.0005)$ increase after $10 \mathrm{~d}$ of testosterone exposure. Fig. 3 illustrates the remarkable abundance of primary follicles in the testosterone-treated ovarian cortex. There was also a very large increase in small antral ("D") follicles. Testosterone, however, did not increase the abundance of large antral (preovulatory) follicles ("E", Fig. 2 D). 

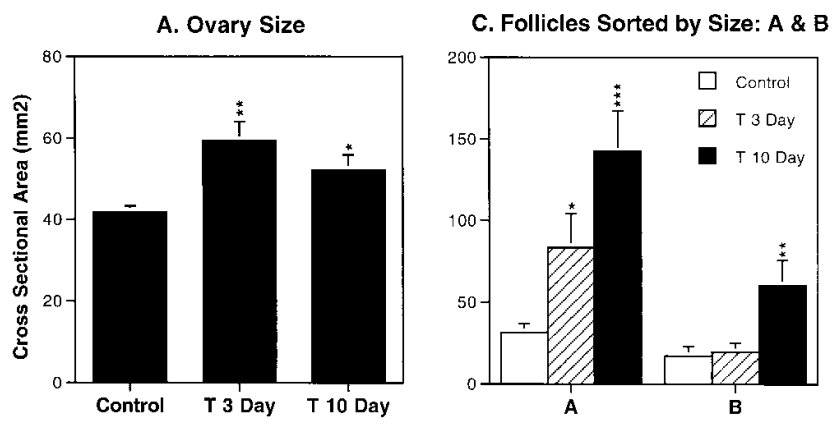

B. Total Follicle Number

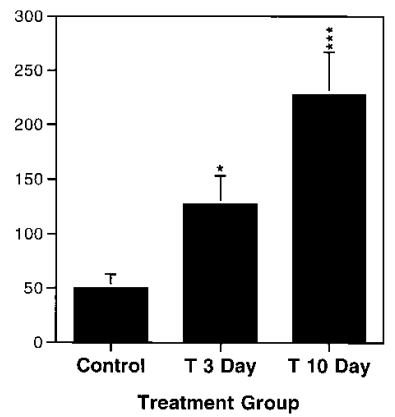

D. Follicles Sorted by Size: C, D \& E

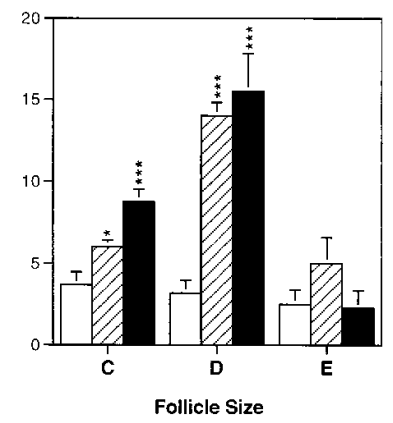

Figure 2. Morphometric changes in ovaries from testosterone-treated animals. ( $A$ ) Ovarian cross-sectional area is significantly increased after just $3 \mathrm{~d}$ and remains elevated after $10 \mathrm{~d}$ of testosterone treatment. (B) Total follicle number progressively increases with duration of testosterone treatment and is significantly increased after both 3 and $10 \mathrm{~d}$ compared with controls. ( $C$ and $D$ ) The effect of testosterone on specific-size follicle classes. Data is presented as means \pm SEM for $n=$ 4-6 monkeys in each group. $* P<0.05$, $* * P<0.005$, $* * * P<0.0005$ compared with control values.

Granulosa and thecal cell proliferation and apoptosis. Ovarian cell proliferation was assessed by immunodetection of the Ki67 antigen, which is a nonhistone nuclear matrix protein expressed in actively dividing cells (19). Testosterone treatment increased granulosa cell proliferation in B-E follicles (Figs. 4 and $5 \mathrm{~A}$ ). No significant Ki67 immunostaining was detected in primary (A) follicles in any group. Programmed granulosa cell death was assessed by the in situ detection of DNA fragmentation using the TUNEL system (20). Testosterone treatment was not associated with increased granulosa cell apoptosis and actually prevented the increase in apoptosis typical of small antral (class D) follicles in controls (Fig. 4 and 5 B).

Both the thickness of the thecal layer and thecal cell proliferation (Ki67 index) were increased in testosterone-treated animals (Fig. 6 and $7 A$ ). Apoptotic cells were not appreciable in the thecal layers of control or testosterone-treated animals.

Comparison of testosterone and DHT effects on follicular growth characteristics. Testosterone levels were similar to normal-cycling women in control animals and were greatly elevated in the high dose, 3-d group, and less elevated but still pharmacological in the 10-d testosterone group (Table II). To determine the effects of less extreme androgen levels on follicular growth, and to compare testosterone and DHT with respect to growth-stimulating potency, we treated two new groups of monkeys with testosterone and DHT. With comparable systemic levels in the 400-600 ng/dl range, DHT and testosterone effects were equal (Table II). Both androgens significantly increased numbers of A- and D-sized follicles, although to a lesser extent than the previous higher dose or longer duration experiments, and both stimulated granulosa cell proliferation and suppressed apoptosis to a similar degree (Table II). This data shows that testosterone's anabolic effects on the ovary are androgen receptor mediated and not due to aromatization of testosterone to estradiol. Furthermore, estradiol levels were profoundly reduced in testosterone-treated monkeys (Table II), suggesting that there was little aromatization occurring either peripherally or in the ovary, probably due to suppression of follicle-stimulating hormone by high androgen levels.

Analysis of ovarian cycle stage effects. Since high dose testosterone treatment suppresses gonadotropins (19), it is not clear that testosterone-treated animals can be classified into valid cycle stages for comparison with controls. Notably, the original studies comparing ovaries from testosterone-treated women to age-matched controls did not attempt to control for cycle stage (17-19). The composition of treatment groups at the start of the study in terms of follicular and luteal phase animals (defined as $\mathrm{P} 4<1.5 \mathrm{ng} / \mathrm{ml}$ for follicular and $\mathrm{P} 4 \geq 1.5 \mathrm{ng}$ / $\mathrm{ml}$ for luteal) is shown in Table II. The fact that large, statistically significant treatment effects were obtained despite the admixture of cycle stages in these groups argues that gonadotropins or cycle stage are not critical variables in androgen's effects on small follicle growth. To attempt to control for possible cycle variation, we compared follicular stage controls $(n=6)$ to follicular T-treated animals (pooling 3- and 10-d treated, $n=5$ ). Treatment effects were of the same magnitude and statistical significance in this analysis; e.g., A follicle number, Con-F $=25.6 \pm 1.81$ vs. $\mathrm{T}-\mathrm{F}=126.4 \pm 23.67(P=0.0028)$;

Table I. Follicle Classification

\begin{tabular}{|c|c|c|c|}
\hline Follicle class & Name & Diameter & Description \\
\hline & & $\mu m$ & \\
\hline A & Primary & $50-100$ & Less than two layers of cuboidal GC with no thecal layer. \\
\hline $\mathrm{B}$ & Preantral & $101-380$ & Three to six layers of cuboidal GC; definitive thecal layers emerges. \\
\hline $\mathrm{C}$ & Periantral & $381-620$ & More than six layers of cuboidal GC; definitive thecal layer; antral cavities began to form. \\
\hline $\mathrm{D}$ & Small antral & $621-1000$ & $\begin{array}{l}\text { More than six layers of cuboidal GC with columnar appearing GC at border of basement membrane; } \\
\text { definitive thecal layer; all follicles have antral cavities. }\end{array}$ \\
\hline $\mathrm{E}$ & Large antral & $>1000$ & Mature graffian follicles with well developed granulosa, thecal, and antral elements. \\
\hline
\end{tabular}

Follicle size was measured as described in Methods. The largest diameter measured from basement membrane to basement membrane (not including the thecal layer) was used to categorize each follicle. GC, granulosa cells. 


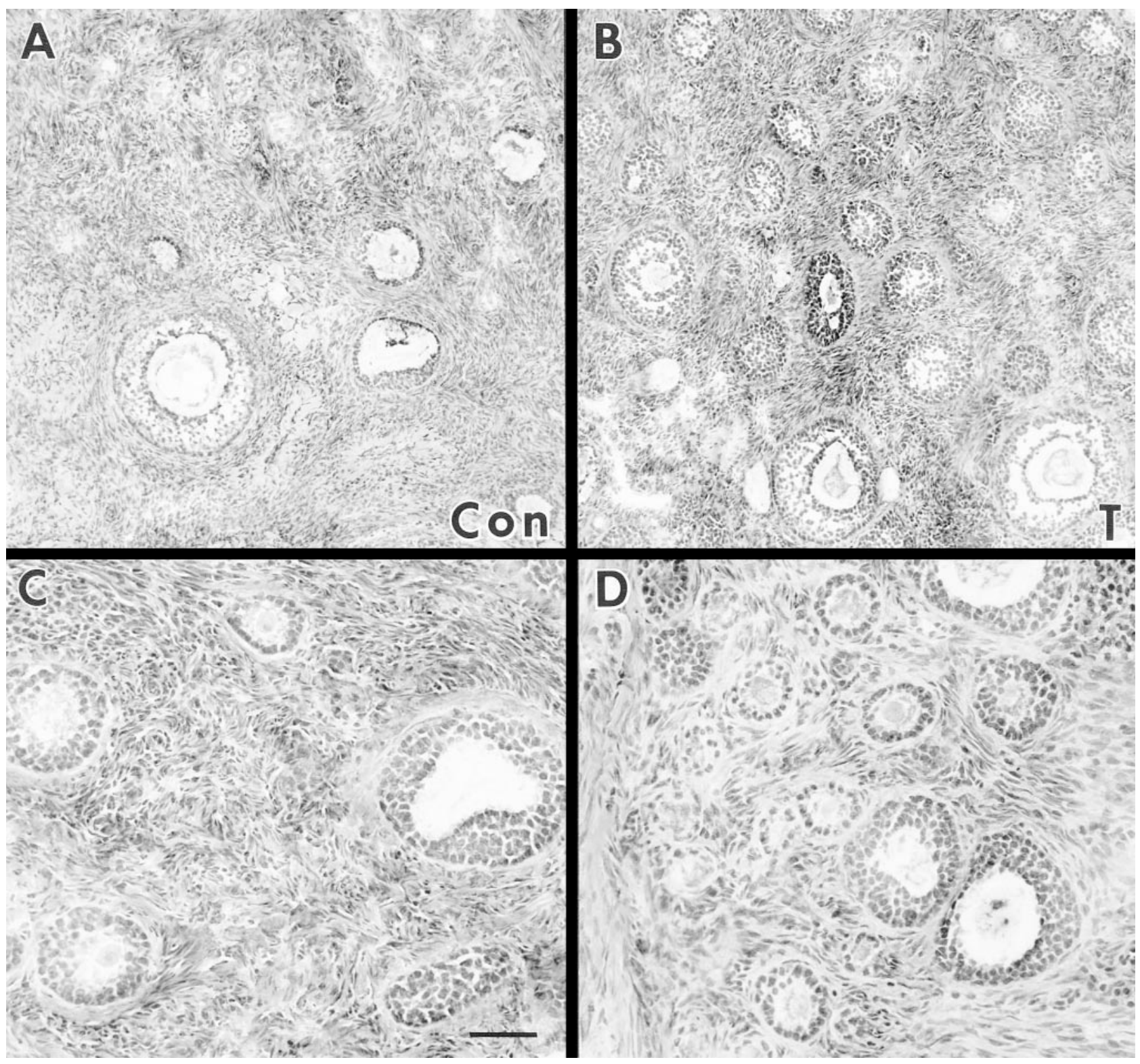

Figure 3. Effects of testosterone on the recruitment of follicles into development. Representative samples from control $($ Con, $A$ and $C)$ and testosterone-treated ( $T, B$ and $D$ ) animals. Testosterone induces an increase in the number of class A or primary follicles. Bar $=100 \mu \mathrm{m}$ for $A$ and $B$ and $50 \mu \mathrm{m}$ for $C$ and $D$.

$\mathrm{D}$ follicle number, Con-F $=3.75 \pm 0.854$ vs. $\mathrm{T}-\mathrm{F}=13.4 \pm 0.872$ $(P<0.0001)$; Ki67 index in D follicles, Con-F $=21.0 \pm 2.74$ vs. $\mathrm{T}-\mathrm{F}=46.6 \pm 3.26(P=0.0007)$; apoptotic index in $\mathrm{D}$ follicles, Con-F $=57.5 \pm 3.86$ vs. $21.4 \pm 1.6(P<0.0001)$.

\section{Discussion}

This study has shown that short-term androgen treatment stimulates early stages of primate ovarian follicular growth, apparently independently of cycle stage or gonadotropin effect. Androgen treatment resulted in significant increases in the number of small growing preantral and antral follicles and increased granulosa and theca cell proliferation in testosterone- and DHT-treated groups. There was no indication of increased follicular atresia; in fact to the contrary, granulosa- programmed cell death was significantly reduced in the androgen-treated monkeys. These findings show that, over the short term at least, androgens are not atretogenic and actually stimulate the growth and survival of small follicles. The concept that androgens are atretogenic has been difficult to reconcile with the fact that hyperandrogenic women have increased numbers of healthy-appearing follicles in all stages of development (11), with normal proliferative and steroidogenic capacities $(21,22)$ and ability to respond to follicle-stimulating hormone (23-25). The present study provides a new explanation for the pathogenesis of PCOS-type ovaries by showing that androgens stimulate early, presumably gonadotropin-independent, stages of follicular development.

The fact that androgen receptors are present in primate ovary granulosa and thecal cells $(26,27)$ supports the view that 

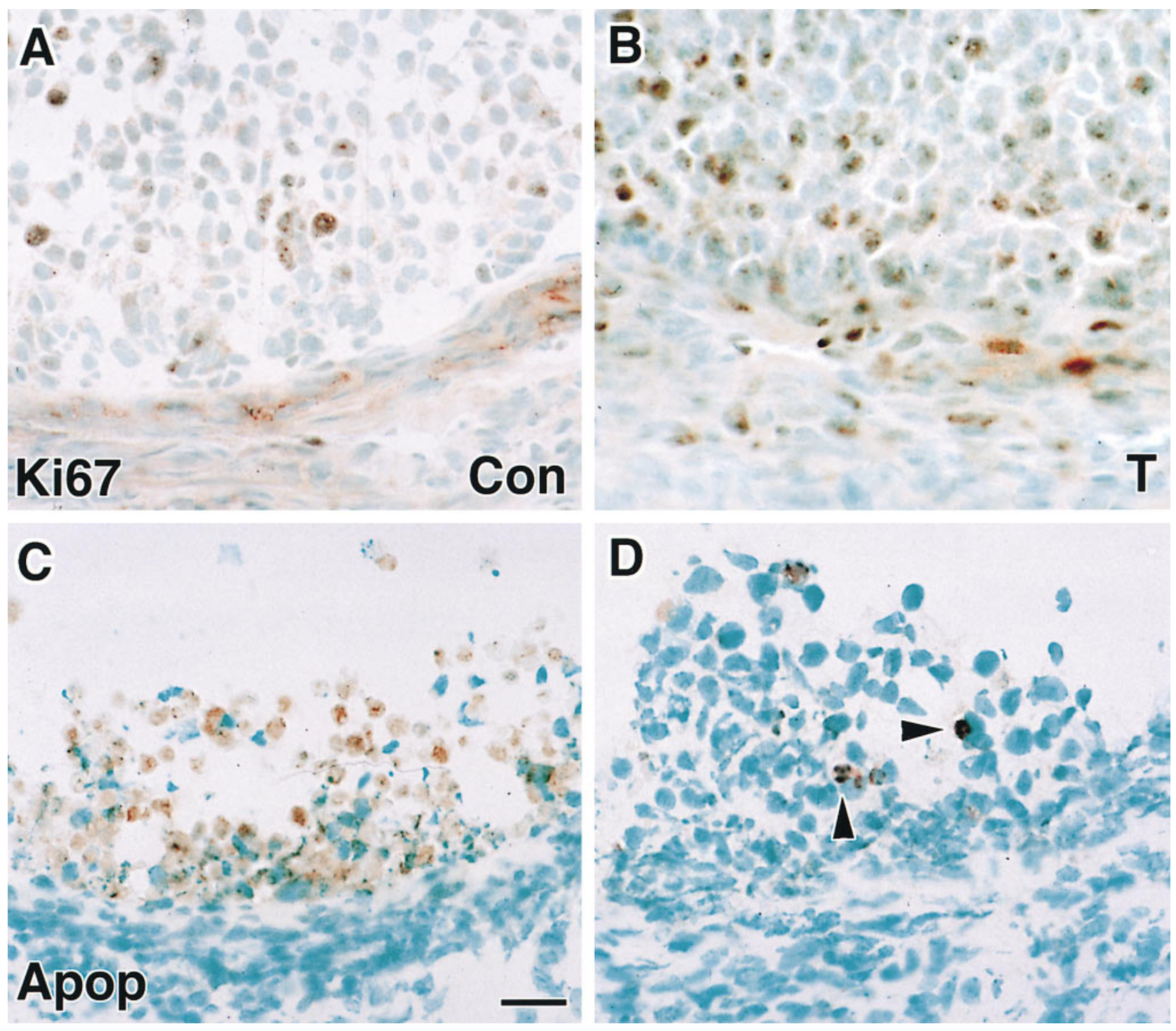

Figure 4. Effects of testosterone on proliferation $(A$ and $B)$ and programmed cell death $(C$ and $D)$ in the primate follicle. Representative photomicrographs of ovary sections from control (Con, $A$ and $C$ ) and testosterone-treated $(T, B$ and $D)$ animals. The immunostaining for both Ki67 and digoxigenin nucleotides appears as a nuclear brown stain. Many of the nuclei in the apoptosis stain look pyknotic or fragmented (arrowheads). The percentage of Ki67-positive granulosa cells (GC) is significantly greater in the testosterone-treated group, while apoptotic GC are significantly less abundant in the testosterone-treated tissue. Bar $=25 \mu \mathrm{m}$.

androgens have direct effects on follicular development. Moreover, we have recently shown that androgen receptor gene expression is positively correlated with follicular growth and granulosa cell proliferation and negatively correlated with follicular atresia and granulosa cell apoptosis in the primate ovary (28), providing additional evidence that the androgen receptor is involved with follicular growth. It is unlikely that testosterone's effects were mediated by estradiol derived from ovarian or peripheral aromatization, since estradiol levels are profoundly reduced in the androgen-treated animals. Furthermore, estrogens do not have growth-promoting effects and may actually inhibit the growth of primate ovary follicles(5-7). Finally, and most definitively, the nonaromatizable androgen DHT has growth-promoting effects equal to those of testosterone, strongly suggesting that these are androgen receptormediated effects.
The supression of estradiol synthesis in androgen-treated monkeys is likely due to the suppression of follicle-stimulating hormone by high circulating androgen levels, as seen in women with elevated testosterone levels $(14,18)$. Despite the suppression of gonadotropins, testosterone-treated women (16-18) and monkeys (shown in the present study) have increased numbers of developing follicles, suggesting that androgens stimulate gonadotropin-independent follicular growth in the primate ovary. A number of observations suggest that early stages of follicular growth are gonadotropin independent (reviewed in reference 1). For example, small antral follicles develop in hypophysectomized fetal monkeys, in girls $<6 \mathrm{yr}$, and in women with panhypopituitarism or Kallman's syndrome. Follicles normally grow at a very slow basal rate through early stages of development and accelerate the growth rate dramatically, under gonadotropin stimulus, at the time of selection (1). 
A

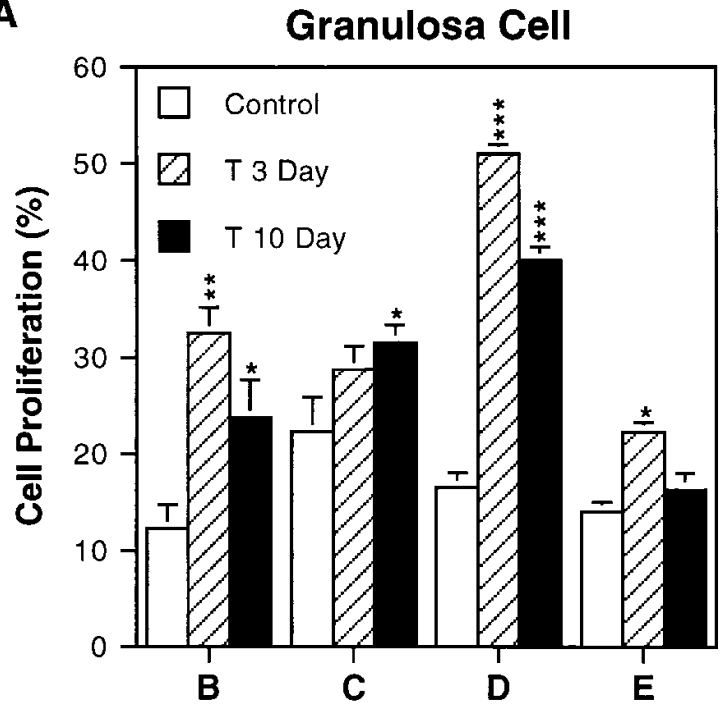

B

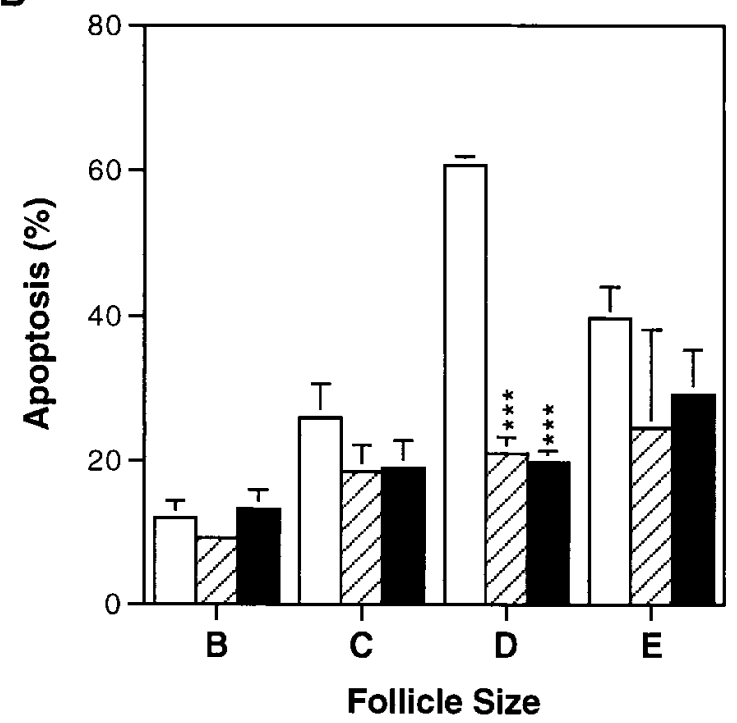

Figure 5. Quantitation of testosterone's effect on granulosa cell proliferation $(A)$ and apoptosis $(B)$.The number of Ki67-positive granulosa cell nuclei per 100 defines the proliferation index. The most pronounced effect of testosterone on granulosa cell proliferation was in small antral " $\mathrm{D}$ " follicles $(A)$. Apoptotic index represents the number of apoptotic (digoxigenin-positive) granulosa cell nuclei per 100 . Testosterone produced significant decreases in granulosa cell apoptosis in small antral D-sized follicles $(B)$. Data represents means \pm SEM for $n=4-6$ monkeys in each group. $* P<0.05$; $* * P<0.005 ; * * * P<$ 0.0005 compared with control.

From the results of the present study, we infer that androgens accelerate the basal growth rate of early, gonadotropin-independent stages of follicle development. Interestingly, the present study also shows that androgens suppress granulosa cell apoptosis, at least in the short term. This finding is consistent with serial ultrasound observations in women with PCOS (29), showing prolonged survival of small antral follicles, which in normal-cycling women either grow rapidly to become dominant follicles or collapse in atresia. If the exposure to androgen excess continued for a prolonged period, these follicles with hyperplastic thecal-interstitial components eventually must collapse back into the ovarian stroma, leading to the stromal hypertrophy typical of PCOS and chronic testosterone treatment $(11,12,17-19)$.

Most women with PCOS do not have extraovarian hyperandrogenism as a cause of the ovarian syndrome. These women presumably have local ovarian hyperandrogenism due to genetic or insulin-induced androgenic enzyme overactivity leading to excessive follicular growth and PCOS (reviewed in reference 30). Support for the concept that androgens per se cause the ovarian pathology of PCOS is provided by a recent study showing that treatment of young women with PCOS with androgen receptor blockade (flutamide) results in normalization of ovarian morphology by ultrasound and restoration of normal cyclic ovarian function (31). Thus, it seems likely that in PCOS, enhanced thecal-interstitial androgen production stimulates an abnormally large cohort of developing follicles, which continuously produce androgens but fail to show the normal progression to estradiol production and ovulation. This arrest of follicular development in PCOS is likely due to disruption of the hypothalamic pituitary-ovary axis caused by elevated systemic androgen levels from the excessive number of developing follicles. Support for this view is provided by the fact that surgical reduction of cohort size by wedge resection often restores cyclic ovarian function and fertility (32). These follicles are fully able to respond to gonadotropins, as shown by the observation that women with PCOS frequently "hyperrespond" to gonadotropin stimulation during in vitro fertilization cycles, probably because of the increased numbers of "selectable" follicles present in their ovaries $(23-25)$.

A previous study tried to establish a model for PCOS in the rhesus monkey by treating the animals with testosterone to achieve systemic levels in the typical PCOS range (80-115 ng/ dl) and found no obvious effects on ovarian morphology (33). However, the circulating testosterone levels seen in PCOS represent the effect, not the cause, of the ovarian pathology, and the intraovarian androgen concentrations stimulating excess follicular growth in PCOS are certainly much higher. We used higher androgen doses to model the situation of testosteronetreated transsexuals and, in so doing, have probably come much closer to simulating the androgen levels occurring in the follicular microenvironment.

In summary, this study has shown that androgens, in addition to serving as essential precursors to estrogen biosynthesis, have dramatic, androgen receptor-mediated trophic effects upon follicle development in the rhesus monkey ovary. These findings help explain the pathogenesis of follicular hyperplasia in PCOS and may provide new insights as to mechanisms governing normal follicle development.

\section{References}

1. Gougeon, A. 1996. Regulation of ovarian follicular development in primates: facts and hypotheses. Endocr. Rev. 17:121-155.

2. Wallach, E.E., and C. Noriega. 1970. Effects of local steroids on follicular development and atresia in the rabbit. Fertil. Steril. 21:253-267.

3. Bradbury, J.T. 1961. Direct action of estrogen on the ovary of the immature rat. Endocrinology. 68:115-120.

4. Smith, B.D., and J.T. Bradbury. 1961. Ovarian weight response to varying doses of estrogens in intact and hypophysectomized rats. Proc. Soc. Exp. Biol. Med. 107:946-949.

5. Dierschke, D.J., C.L. Chaffin, and R.J. Hutz. 1994. Role and site of estrogen action in follicular atresia. Trends Endocrinol. Metab. 5:215-219. 
Table II. Summary of Experimental Data on Androgen Effects on Primate Follicular Growth

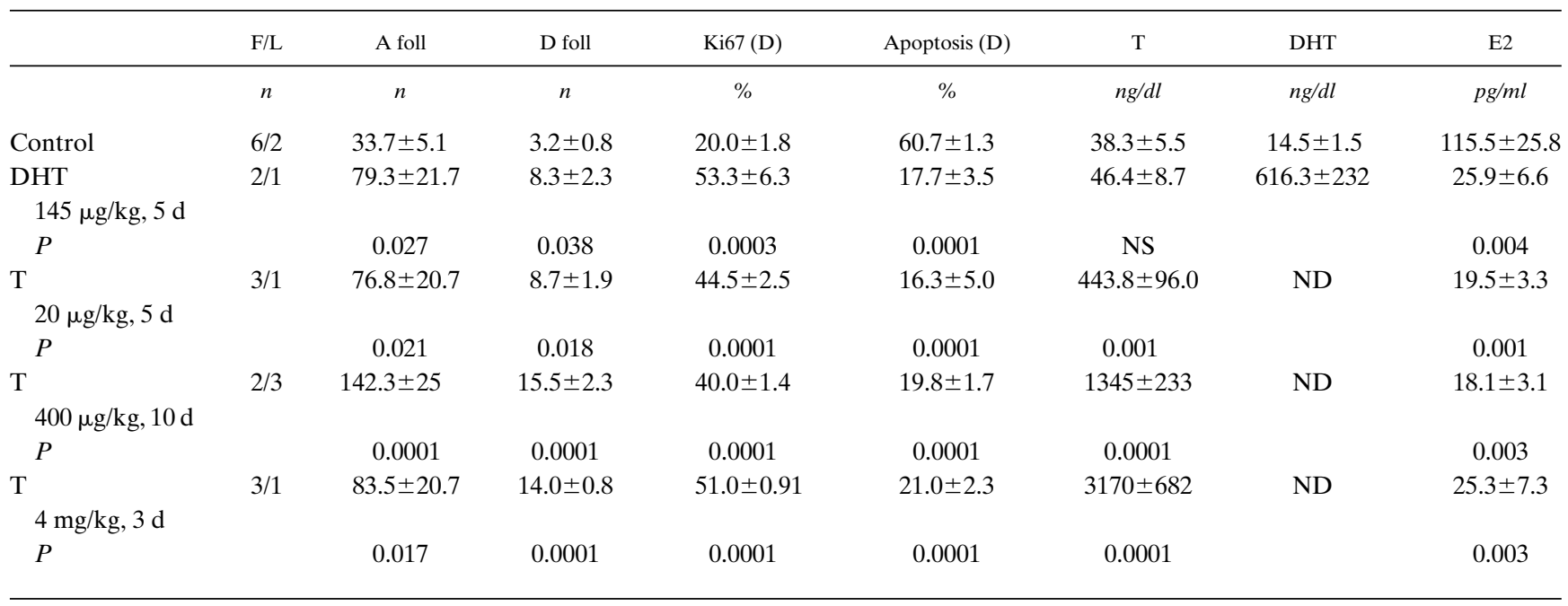

This table compares the effects of similar DHT and testosterone levels in a 5-d experiment (rows 2 and 3) on selected aspects of follicle growth. These include the numbers of A- and D-size follicles, Ki67 (proliferation), and apoptosis indices (expressed as percent positive granulosa cells in D follicles). Data from earlier experiments using higher dose testosterone are shown in rows 4 and 5. Also shown are the number of animals in each group, each group's composition in terms of follicular (F) vs. luteal (L) stages, and hormone levels for each group at the time of ovariectomy. Androgen doses and duration of treatment are indicated in the left-most column. Group means were compared by analysis of variance and $P$ values are shown for each group compared with control. There were no statistically significant differences in outcome parameters between DHT and T 5-d experiments. Direct comparisons between other groups were not made due to the differing durations of the experiments. ND, not done.

6. Zelinski-Wooten, M.B., and R.L. Stouffer. 1996. Steroid receptors and action in the primate follicle. Trends Endocrinol. Metab. 7:177-183.

7. Koering, M.J., D.R. Danforth, and G.D. Hodgen. 1994. Early follicle growth in the juvenile macaca monkey ovary: the effects of estrogen priming and follicle-stimulating hormone. Biol. Reprod. 50:686-694.

8. Hillier, S.G., and G.T. Ross. 1979. Effects of exogenous testosterone on ovarian weight, follicular morphology and intraovarian progesterone concentration in estrogen-primed hypophysectomized immature female rats. Biol. Reprod. 20:261-268.

9. Billig, H., I. Furuta, and J.W. Hsueh. 1993. Estogens inhibit and andro- gens enhance ovarian granulosa cell apoptosis. Endocrinology. 133:2204-2212.

10. Susan, A.J., B.Sc. Daniel, and D.T. Armstrong. 1986. Androgens in the ovarian microenvironment. Semin. Reprod. Endocrinol. 4:89-100.

11. Hughesdon, P.E. 1982. Morphology and morphogenesis of the SteinLeventhal ovary and of so-called "hyperthecosis". Obstet. Gynecol. Surv. 37:5977.

12. Erickson, G.F., and S.S.C. Yen. 1984. New data on follicle cells in polycystic ovaries: a proposed mechanism for the genesis of cystic follicles. Semin. Reprod. Endocrinol. 2:231-243.

13. Lobo, R.A. 1984. The role of the adrenal in polycystic ovarian syn-

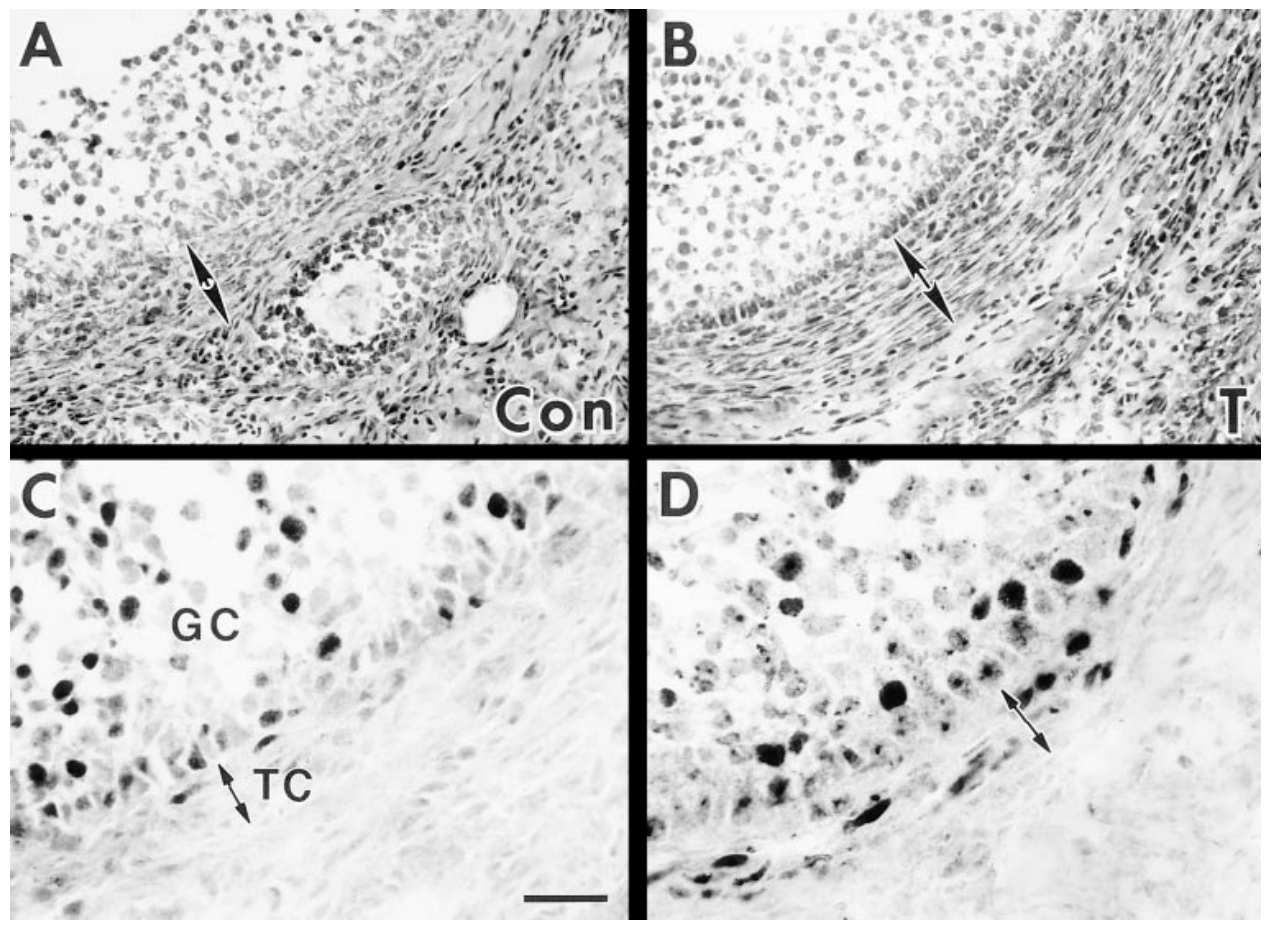

Figure 6. Comparison of thecal layer thickness $(A$ and $B)$ and thecal cell proliferation $(C$ and $D)$ in control (Con, $A$ and $C$ ) and testosterone-treated ( $T, B$ and $D$ ) ovaries. $A$ and $B$ are photomicrographs of hematoxylin and eosin-stained ovarian sections showing the thecal layer marked by double-headed arrows. $C$ and $D$ are photomicrographs of Ki67 immunostained sections, showing Ki67-positive nuclei in the thecal cells $(T C)$. Bar $=50 \mu \mathrm{m}$ for $A$ and $B$ and $25 \mu \mathrm{m}$ for $C$ and $D$. 
A

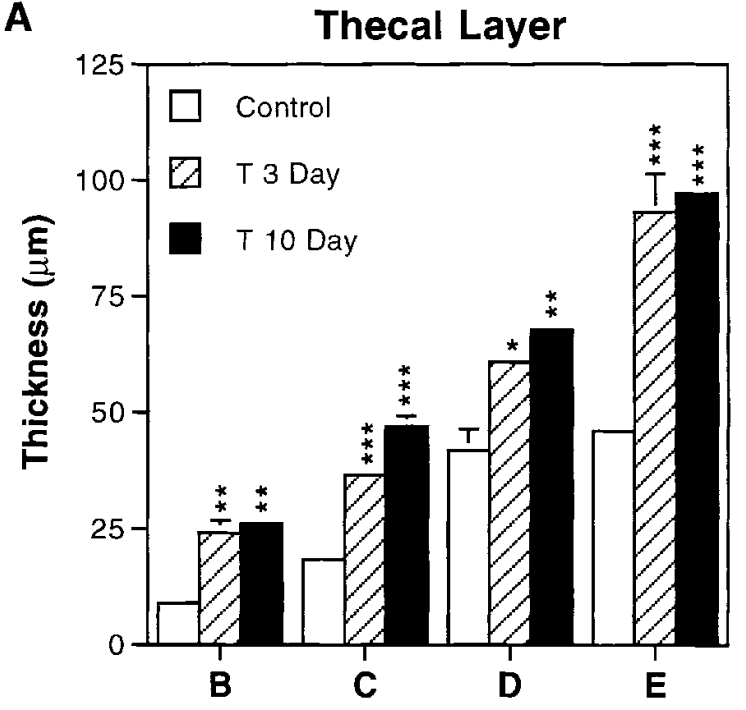

B

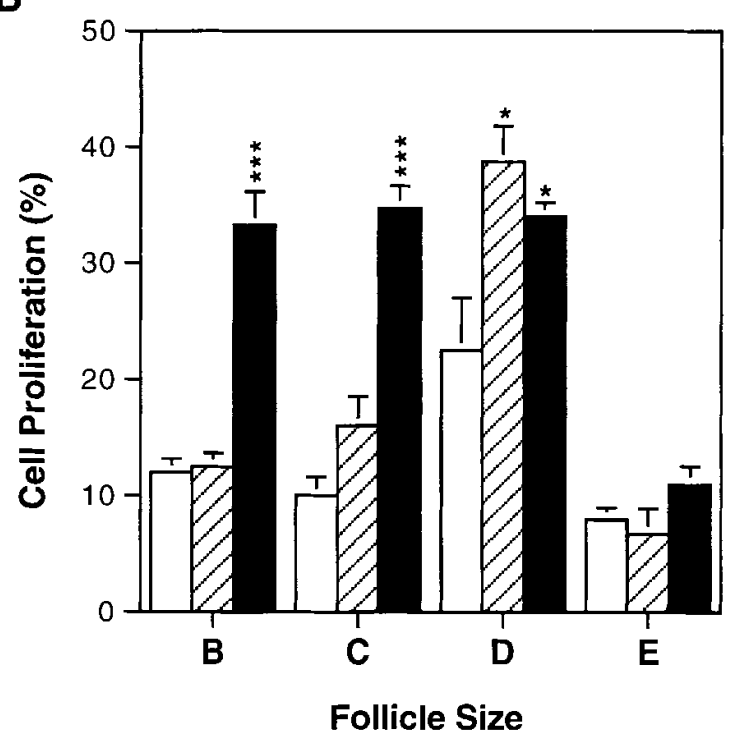

Figure 7. Testosterone stimulates thecal-layer growth. $(A)$ Comparing thecal thickness in control and testosterone-treated groups. $(B)$ $\mathrm{Ki67}$, or proliferation index of thecal cells in control and testosteronetreated groups. Data is presented as means \pm SEM for $n=4-6$ monkeys in each group. $* P<0.05 ; * * P<0.005 ; * * * P<0.0005$ compared with control.

drome. Semin. Reprod. Endocrinol. 2:251-262.

14. Dunaif, A., R.E. Scully, R.N. Andersen, D.S. Chapin, and W.F. Crowley. 1984. The effect of continuous androgen secretion on the hypothalamicpituitary axis in woman: evidence from a luteinized thecoma of the ovary. $J$.
Clin. Endocr. Metab. 59:389-393.

15. Kase, N., J. Kowal, W. Perloff, and L.J. Soffer. 1963. In vitro production of androgens by a virilizing adrenal adenoma and associated polycystic ovaries. Acta Endocrinol. 44:15-19.

16. Futterweit, W., and L. Deligdisch. 1986. Histopathological effects of exogenously administered testosterone in 19 female to male transsexuals. J. Clin. Endocrinol. Metab. 62:16-21.

17. Pache, T.D., S. Chadha, L.J.G. Goorens, W.C.J. Hop, K.W. Jaarsma, H.B.R. Dommerholt, and B.C.J.M. Fauser. 1991. Ovarian morphology in longterm androgen-treated female to male transsexuals. A human model for the study of polycystic ovarian syndrome? Histopathology. 19:445-452.

18. Spinder, T., J.J. Spijkstra, J.G. Van Den Tweel, C.W. Burger, H. Van Kessel, P.G.A. Hompes, and L.J.G. Gooren. 1989. The effects of long term testosterone administration on pulsatile luteinizing hormone secretion and on ovarian histology in eugonadal female to male transsexual subjects. J. Clin. Endocr. Metab. 69:151-157.

19. Gerdes, J., L. Li, C. Schlueter, M. Duchrow, C. Wohlenberg, C. Gerlach, I. Stahmer, S. Kloth, E. Brandt, and H.D. Flad. 1991. Immunobiochemical and molecular biologic characterization of the cell proliferation-associated nuclear antigen that is defined by monoclonal antibody Ki-67. Am. J. Pathol. 138:867873 .

20. Schmitz, G.G., T. Walter, R. Seibl, and C. Kessler. 1991. Nonradioactive labeling of oligonucleotides in vitro with the hapten digoxigenin by tailing with terminal transferase. Anal. Biochem. 192:222-231.

21. Pache, T.D., W.C. Hop, F.H. de Jong, R.A. Leerentveld, H. Van Geldorp, T.M.M. Van de Kamp, L.J.G. Gooren, and B.C.J.M. Fauser. 1992. $17 \beta$-Oestradiol, androstenedione and inhibin levels in fluid from individual follicles of normal and polycystic ovaries, and in ovaries from androgen treated female to male transsexuals. Clin. Endocrinol. 36:565-571.

22. Takayama, K., T. Fukaya, H. Sasano, Y. Funayama, T. Suzuki, R. Takaya, Y. Wada, and A. Yajima. 1996. Immunohistochemical study of steroidogenesis and cell proliferation in polycystic ovarian syndrome. Hum. Reprod. (Oxf.). 11:1387-1392.

23. McDougall, M.J., S.L. Tan, A. Balen, and H.S. Jacobs. 1993. A controlled trial comparing patients with and without polycystic ovaries undergoing in vitro fertilization. Hum. Reprod. (Oxf.). 2:233-237.

24. Buyalos, R.P., and C.T. Lee. 1996. Polycystic ovary syndrome: pathophysiology and outcome with in vitro fertilization. Fertil. Steril. 65:1-10.

25. Van Der Meer, M., P.G.A. Hompes, J.A.M. De Boer, R. Schats, and J. Schoemaker. 1998. Cohort size rather than follicle-stimulating hormone threshold level determines ovarian sensitivity in polycyctic ovary syndrome. J. Clin. Endocrinol. Metab. 83:423-426.

26. Hillier, S.G., M. Tetsuka, and H.M. Fraser. 1997. Location and developmental regulation of androgen receptor in primate ovary. Hum. Reprod. (Oxf.). 12:107-111.

27. Hild-Petito, S., N.B. West, R.M. Brenner, and R.L. Stouffer. 1991. Localization of androgen receptor in the follicle and corpus luteum of the primate ovary during the menstrual cycle. Biol. Reprod. 44:561-568.

28. Weil, S.J., K. Vendola, J. Zhou, O.O. Adesanya, J. Wang, and C.A. Bondy. 1998. Androgen receptor gene expression in the primate ovary: cellular localization, regulation and functional correlations. J. Clin. Endocrinol. Metab. In press.

29. Pache, T.S., W.C.J. Hop, J.W. Wladimiroff, J. Schipper, and C.J.M. Fauser. 1991. Transvaginal ultrasonography and abnormal ovarian appearance in menstrual cycle disturbances. Ultrasound Med. Biol. 17:589-593.

30. Dunaif, A. 1995. Hyperandrogenic anovulation (PCOS): a unique disorder of insulin action associated with an increased risk of non-insulin-dependent diabetes mellitus. Am. J. Med. 98:33S-39S.

31. de Leo, V., D. Lanzetta, D. D'Antona, A. la Maarca, and G. Morgante. 1998. Hormonal effects of flutamide in young women with polycystic ovary syndrome. J. Clin. Endocrinol. Metab. 83:99-102.

32. Donesky, B.W., and E.Y. Adashi. 1995. Surgical ovulation induction in PCOS: wedge resection revisited in the age of laparoscopy. Fertil. Steril. 63:439463.

33. Faiman, C., F.I. Reyes, D.W. Dent, G.B. Fuller, W.C. Hobson, and J.A. Thliveris. 1988. Effects of long-term testosterone exposure on ovarian function and morphology in the rhesus monkey. Anat. Rec. 222:245-251. 